\title{
Não leve flores
}

\author{
Rafael Amorim ${ }^{2}$
}

Resumo: A presente escrita aborda de maneira crítica a exposição "Não leve flores", proposta pela dupla de artistas visuais Rodrigo Pinheiro e Ton Zaranza, durante o último mês de março na Galeria Refresco, Rio de Janeiro. Contemplada pelo Edital de Chamada Aberta 2020, a exposição dispôs no espaço expositivo uma série de fotografias analógicas a retratar corpos dissidentes e seus testemunhos sob a perspectiva das últimas eleições presidenciais. Portanto, esta crítica é costurada pelo interesse em evidenciar uma escrita relato dessa exposição como resultado de eventos caros aos corpos retratados em "Não leve flores" e pretende apontar para o agrupamento desses corpos sob a noção de álbum de família.

Palavras-chave: crítica de arte, exposição, fotografia contemporânea, álbum de família

\section{Don't take flowers}

Abstract: This essay critically addresses the exhibition "Não leve flores" (don't take flowers), proposed by the visual artists duo Rodrigo Pinheiro and Ton Zaranza, during the last month of March at Galeria Refresco, Rio de Janeiro. Contemplated by the Open Call 2020, the artistic show placed in the exhibition space a series of analog photographs portraying dissident bodies and their testimonies from the perspective of the last presidential elections in Brazil. Therefore, this criticism is sewn by the interest in showing a written report of this exhibition as a result of events of great concern to the bodies portrayed in "Não leve flores" and intends to point to the grouping of these bodies under the idea of a family album.

Keywords: art critic, exhibition, contemporary photography, family album

1 Exposição Não leve flores, de Rodrigo Pinheiro e Ton Zaranza. Contemplada pelo Edital de Chamada Aberta 2020 da Galeria Refresco, RJ (Rua Sara, n.18, Santo Cristo - Rio de Janeiro) no período de 12 a 15 de março de 2020.

2 Além de artista visual, Rafael é poeta, morador de Padre Miguel - zona oeste carioca - e graduando pela Escola de Belas Artes da UFRJ (2014-2020). Durante 2019 fez parte do Programa de Formação Gratuito da Escola de Artes Visuais do Parque Lage, foi curador da exposição coletiva "Terreno baldio: experiência n.1" na Pinacoteca da Universidade Federal de Viçosa e propositor do projeto de residência artística "Terreno baldio: experiência n.2" no Centro Cultural da UFMG, em Belo Horizonte. Tem sua prática voltada para as relações entre arte, curadoria e poesia, investigando conexões entre o fazer artístico, o cotidiano e a escrita. Universidade Federal do Rio de Janeiro (UFRJ/ EBA). E-mail: amorimrafael.belasartes@gmail.com. ORCID:https://orcid.org/0000-0002-0914-2908. Lattes iD: http://lattes.cnpq.br/7636952778790684. Rio de Janeiro, Brasil. 
"porque tudo dentro era ruptura do quase..." 1

"É lícito cantar de amor quando o rei é cruel em seu reinado?" (2003, p.31), indaga Hilda Hilst, para em seguida responder a si mesma: "Se o canto das gentes se juntasse à audácia fremente do meu canto, talvez o rei cruel nem mais reinasse." (Ibidem). A exposição do fotógrafo Rodrigo Pinheiro, em parceria com o também artista Ton Zaranza, parece existir na dimensão de uma canção sobre as urgências do coletivo em meio à recepção dos resultados das urnas nas últimas eleições.

Como um álbum de família, Não leve flores (título tomado emprestado da composição de Belchior) devolve ao mundo uma série de fotografias analógicas que retrata corpos sob a perspectiva do derradeiro 28 de outubro de 2018: são homens e mulheres transexuais, travestis, pessoas não binárias, lésbicas, homo e bissexuais, pansexuais e demais narrativas dissidentes que questionam as construções de gênero e de sexualidade.

Naquele dia, nos entregavam não só a conclusão de um ano eleitoral pautado na disseminação de notícias falsas via redes sociais e discursos de ódio contra minorias, mas nos condicionavam aos quatro anos de vigência deste pedaço de futuro ao qual vivemos. Assim sendo, os retratos de Rodrigo tomam forma enquanto conjunto a partir desse evento e parecem evidenciar a construção de uma rede de afetos, cuidadosamente tramada, como resposta à incerteza e ao medo que perpassou estes corpos.

Se antes o retrato em família, "para além do seu uso privado, serviu em grande medida para afirmar valores que refletiam e reforçavam o ideário da família pilar da sociedade" (GÉO, 2015, n.p), aqui seria necessário começar a olhar para um outro tipo de família que se aglutina a partir de urgências em comum. "Essa, ao desmistificarem a imagem da família-modelo e sua associação a uma grandeza moral e social, favorecem uma revisão crítica dessa imagem" (Ibidem) para dar lugar ao desejo de coletividade diante de um movimento de mudanças que, para o próprio Rodrigo, que escreve no release da exposição, "reverberam no íntimo dos corpos mais vulneráveis à arbitrariedade dessas decisões." 


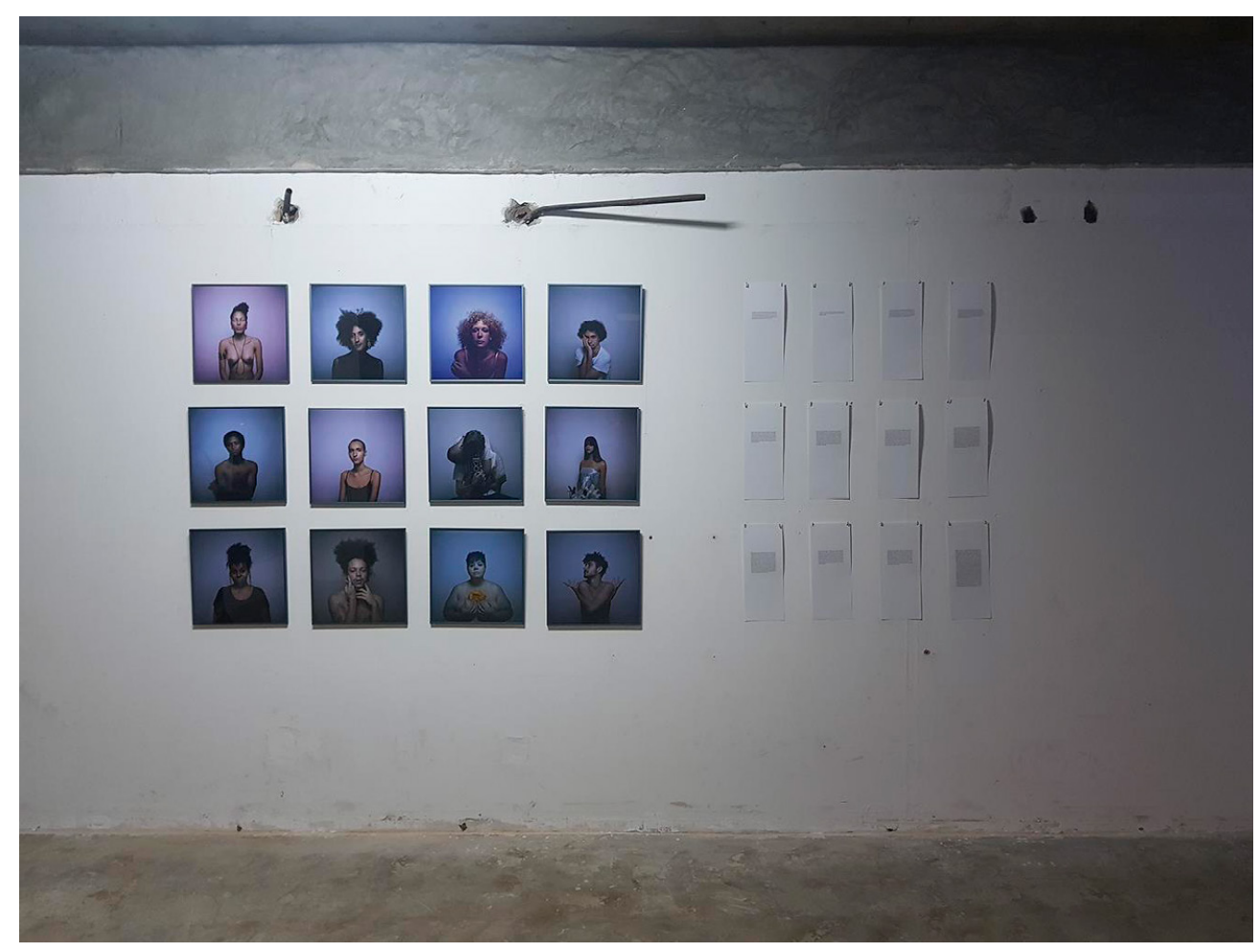

O núcleo familiar evocado em Não leve flores não conta com uma árvore genealógica em sua concepção. Todavia, ele impõe uma reflexão que também nos chega na própria letra a qual o título da exposição referencia:

O inimigo eu já conheço. Sei seu nome, sei seu rosto, residência e endereço. A voz resiste, a fala insiste, você me ouvirá. Não cante vitória muito cedo, não. Nem leve flores para a cova do inimigo. Que as lágrimas do jovem são fortes como um segredo.

Esse lugar reflexivo que se institui, apontado por corpos historicamente marginalizados aproximando-se entre si, nos propõe a lançar um olhar mais delicado sobre questões "que extrapolam o interior do núcleo familiar" (GÉO, 2015, n.p). Em outras palavras, o agrupamento a partir de um evento tão simbólico quanto as últimas eleições talvez denote que a fragilidade desses corpos (que reconhecem seus inimigos em comum), quando partilhada entre si, não denunciaria apenas as mazelas de suas condições, mas ajudaria a reforçar o sentimento de pertencimento.

Mais do que acolher esse estado de fragilidades para se criar o conjunto de imagens dentro de um recorte temporal, é possível apontar que o uso da palavra também tem um forte desempenho no desenvolvimento 


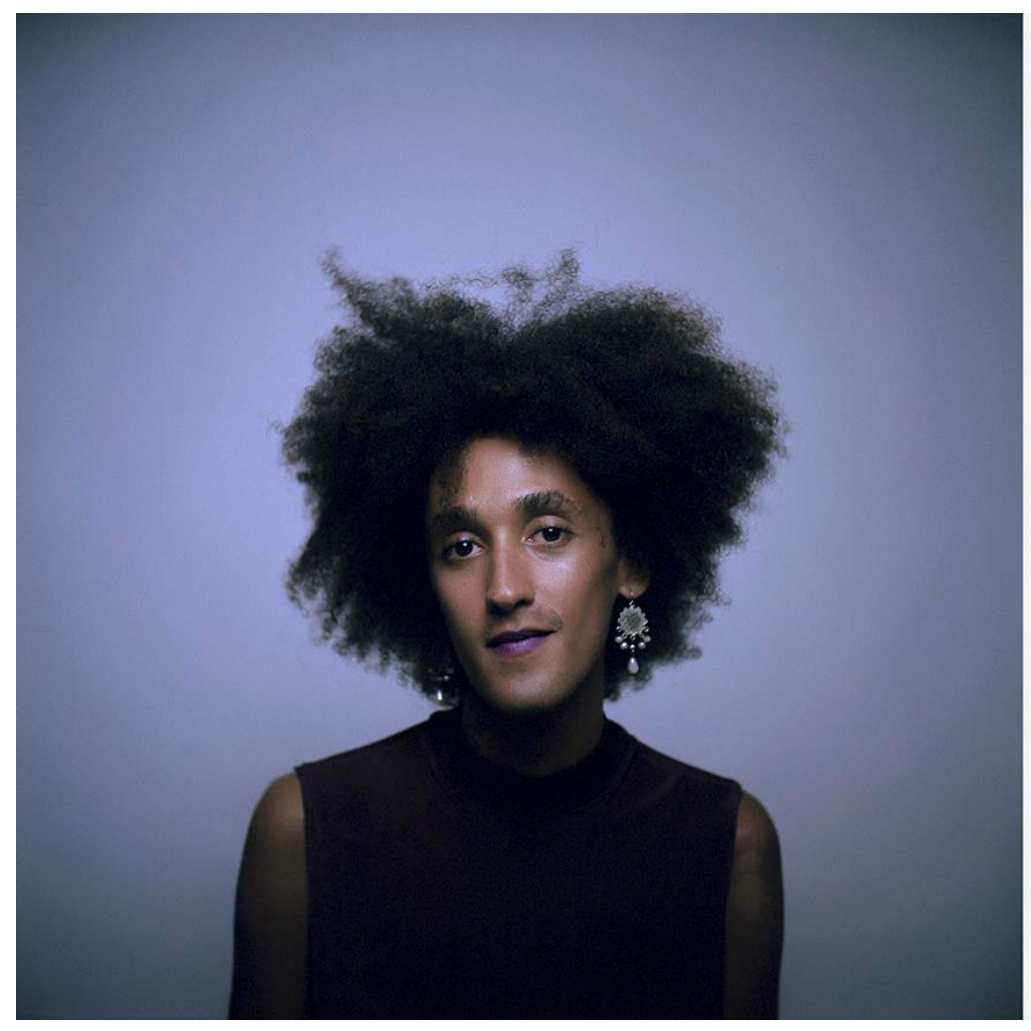

Figuras 2 e 3 Série Não leve flores. Rodrigo Pinheiro, 2019. Filme médio formato. Fonte: https:// rdrgpnhr.com/ naoleveflores/

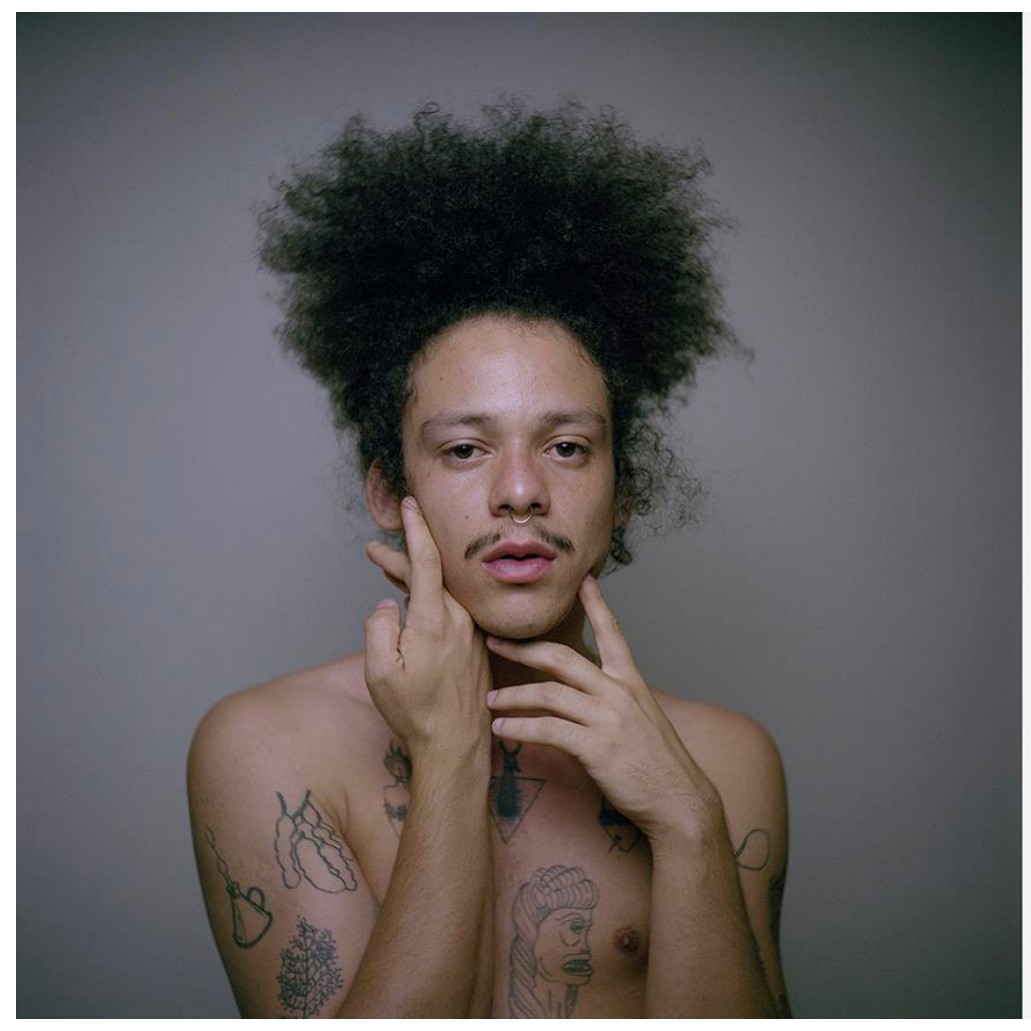

Na rua um cara gritou. Eu estava com os meus familiares indar por ai Era um carac com a a busas do Brasasil. Durante noite, eu fiquei em casa. Lembro que eue meve ex-naquando saiu o resultado. comecamos a chorar e nos ser-
timos bem port termos um ao outro. Foi um dia de se torblecer. Estivamos em nossa casa Comecaram uns as postagens nas redes socialis tambem. Teve um deses. era importante ter um ao outro nescoso mala mou 
daquilo que nos entrega o artista: na exposição, ao lado de cada retrato, como alternativa à ficha técnica, uma legenda relata o que cada uma dessas pessoas estava sentindo ou fazendo durante aquele evento.

"Dia 28 de outubro. Certo? De 2018. Intenso esse dia. Eu estava no morro da conceição. Consigo sentir isso. Mas preciso pensar", relata Sabine Passareli ao ser retratada.

\begin{abstract}
Na rua um cara gritou. Eu estava com os meus familiares, uma tia, meus irmãos, e eles sentiram como é para mim andar por aí. Era um cara com a blusa do Brasil. Durante a noite, eu fiquei em casa. Lembro que eu e meu ex-namorado estávamos rompendo, mas, ao mesmo tempo, quando saiu o resultado, começamos a chorar e nos sentimos bem por termos um ao outro. Foi um dia de se fortalecer. Estávamos em nossa casa. Começaram uns fogos, o bairro começou a gritar - foi horrível. Sem contar as postagens nas redes sociais também. Teve um desesperozinho. Foi isso. A gente se abraçou e falou o quanto era importante ter um ao outro nesse momento. ${ }^{2}$
\end{abstract}

Assim, em Não leve flores, texto e imagem se mostram como partes constitutivas do processo fotográfico, interseccionando-se. Ao situar ali os breves relatos escritos em primeira pessoa, Rodrigo Pinheiro parece criar uma espécie de documento sobre a memória dos corpos em relação à força simbólica de determinados eventos e discursos, mas que os afetam diretamente.

Além de criar um repertório de imagens semelhantes entre si, os textos apresentados na exposição convocam histórias de um mesmo dia percebido sob dezenas de perspectivas. E embora advindos das mais diferentes regiões do país, são textos que em sua maioria versam sobre medo e incerteza, mas também sobre acolhimento e afeto. O caráter desse conjunto textual nos entrega uma espécie de diário escrito a muitas mãos, tratando-se de uma intimidade coletiva que é evidenciada pela pluralidade desse outro modelo de família que se articula para vivenciar junto os momentos de crise que vêm de fora para dentro.

Há de se salientar, também, a presença de dois objetos produzidos digitalmente por Ton Zaranza para a exposição: uma carranca de dentes que tomam quase a mesma proporção da mesma e um sapato com seu salto aguIha modificado intencionalmente. A desproporção de ambos talvez possa 
Figuras 4 e 5 Ton Zaranza. Carranca e Salto, 2019. CGI. Fonte: rdrgpnhr.com/ naoleveflores/
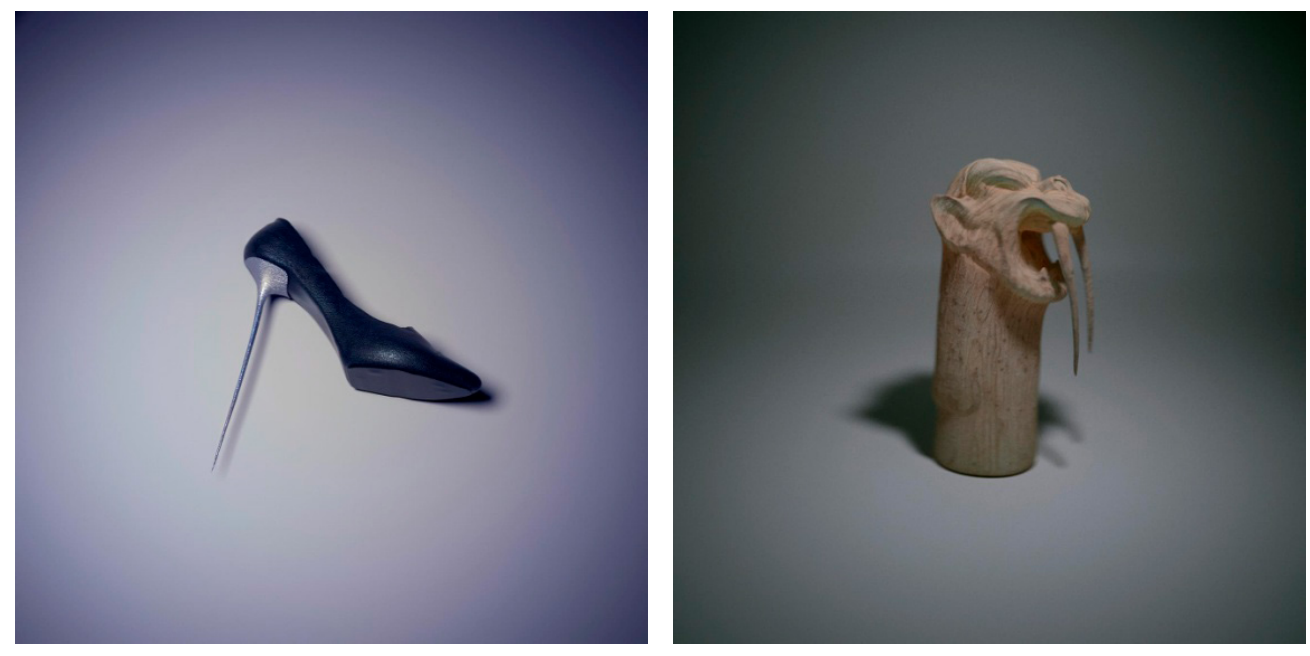

ser encarada como uma alegoria aos tempos vindouros, como objetos de amparo aos quais recorrem os corpos fotografados por Rodrigo Pinheiro.

Enquanto símbolos, o primeiro, uma escultura antropozoomórfica culturalmente encontrada em algumas regiões do Sudeste e Nordeste do país (Ton é natural de Aracati, CE), carregaria consigo o lugar da proteção contra o avanço do discurso neopentecostal sobre as demais manifestações religiosas - pauta muito discutida durante o ano eleitoral e fundamental para a consolidação do modelo de governo que carrega como propaganda a frase "Brasil acima de tudo, Deus acima de todos." O segundo, uma tentativa para se repensar as construções de gênero em que o salto agora viria a ser uma possibilidade de arma para esses corpos em perigo.

Ambos sublinhando a ineficácia dos modelos já caducos que não contemplam os corpos retratados em Não leve flores, de modo a sugerir uma outra iconografia que ampare esses corpos. Nessa nova iconografia questiona-se, ainda que simbolicamente, a responsabilidade dos representantes políticos atuais com relação aos discursos contrários à preservação da memória desse grupo de pessoas. Reivindicando, assim, outras imagens, outros ícones, outras mitologias e nos fazendo questionar: "é rei ainda se na miséria nunca se demora? é rei se foge de nós?” (HILST, 2003, p.32)

\section{Referências}

LIRA, Ana. para caminhar ciclos, 2020. Disponível em: https://rdrgpnhr.com/naoleveflores/ Acesso em: 22 de março de 2020. 
HILST, Hilda. Rútilos. São Paulo: Globo, 2003.

GÉO, Daniella. In Catálogo da exposição Álbum de família / curadoria Daniella Géo. Rio de Janeiro: Centro Municipal de Artes Hélio Oiticica, 2015.

Recebido em 25 de março de 2020 e aceito em 28 de abril de 2020.

Este é um artigo publicado em acesso aberto sob uma licença Creative Commons 